\title{
¿Somos todos griegos...incluso en el exilio? Algunas reflexiones acerca de las "influencias bizantinas" en la plástica hispánica de la Tardoantigüedad y la Alta Edad Media
}

\author{
Iván Pablo LóPEZ PÉReZ \\ Universidad Complutense de Madrid \\ Departamento de Historia del Arte I (Medieval) \\ ibn_corleone2@hotmail.com
}

Durante décadas, el análisis de las obras de arte producidas en Occidente, en especial de aquellas gestadas entre la desaparición del Imperio Romano y el advenimiento del Carolingio, ha estado fuertemente determinado por el establecimiento de una referencia casi constante a las creaciones bizantinas. Esta recurrencia ha llegado a convertirse en una especie de vademécum esclarecedor desplegable en el ámbito estilístico, que ha servido con frecuencia para explicar el carácter y el significado de innumerables expresiones artísticas de la Tardoantigüedad y de la Alta Edad Media. En el momento en el que una obra producida en el Mediterráneo occidental mostraba una calidad de ejecución o planificación digna de ser destacada, inmediatamente y como resultado de un acto casi reflejo, le ha ido asociada la reincidente posdata "influencia bizantina" o "influencia oriental". Parece difícil negar a día de hoy que la invocación al bizantinismo se ha convertido en un lugar común en los modelos explicativos más generalizados de historia del arte, lugar común en cuyas raíces, sin embargo habría que segregar un importante componente de legendarismo historiográfico.

Para encontrar el embrión de esta inercia hay que remontarse a los años finales del siglo XVIII, momento en el cual empiezan a incrementarse los desplazamientos desde Europa hacia tierras entonces bajo dominio otomano. La sistematización de estas travesías terminó por fijar lo que podríamos llamar un tour de Oriente avalado por viajeros ilustres como Chateaubriand ${ }^{1}$, Nerval o Flaubert.

Lo que en un primer momento se manifestó como una atracción estética hacia lo pintoresco de aquellas tierras, pronto pasó a traducirse en un ferviente interés por su historia antigua y medieval. Desde el ámbito heleno, figuras como Adamantios Korais o Constantine Paparrigopoulos ${ }^{2}$ trataron de despojar al mundo griego medieval de la mala fama que Occidente le había atribuido desde Edward Gibbon ${ }^{3}$. Igualmente, y en

1 F.R. CHATEAUBRIAND, De París a Jerusalén, Barcelona, 1982 [París, 1811].

2 C. PAPARRIGOPOULOS, History of the Hellenic Nation, 6 vols, Atenas, 1860-1877.

3 E. GIBBON, The Decline and Fall of the Roman Empire, Londres 1776, 1781, 1788. 
fechas relativamente tempranas, los helenistas centraron sus esfuerzos en establecer una línea consensuada de separación entre las nociones de griego antiguo-clásico y griego medieval-bizantino. Esta labor de diferenciación quedó rápidamente resuelta con relativa nitidez en el dominio de la filología. Sin embargo, no podemos decir lo mismo para la historia del arte. En esta última disciplina los autores occidentales habían encontrado en las raíces clásicas del arte bizantino no solamente una excelente carta de presentación de este ante el academicismo europeo, sino que al mismo tiempo, mediante la extrapolación cronológica de dicho clasicismo, y geográfica del propio bizantinismo, podían despejarse a priori innumerables incógnitas concernientes al arte medieval europeo.

Se iniciaron así las primeras aproximaciones al arte del Oriente cristiano, con publicaciones pioneras como las de André Couchaud ${ }^{4}$ o Melchior de Vogüé ${ }^{5}$, las cuales sentaron las bases de un acercamiento a las creaciones bizantinas en las que fueron privilegiadas algunas ideas como la necesidad de creer en la existencia de una iteración irrefrenable de patrones icónicos o el establecimiento de una inflexión descendente en el arte de Bizancio a partir del siglo VII. Igualmente, los estudiosos del siglo XIX implantaron una visión de las relaciones Oriente-Occidente determinada en distintas oleadas de apogeo de uno, decadencia del otro, y viceversa.

Ya incluso varios años antes de la legendaria expedición al Próximo Oriente de la fragata Arapiles ${ }^{6}$, la curiosidad que los eruditos españoles habían empezado a manifestar hacia el mundo bizantino fue satisfecha con la publicación, en 1847, de El Siglo Pintoresco, donde se recogían una serie de valoraciones estéticas acerca del arte de Bizancio muy próximas a las que acabamos de vincular a la escuela francesa ${ }^{7}$. Así, cuando poco tiempo después Manuel de Assas realizó un prometeico estudio de la escultura decorativa toledana, no dudó en manifestar que esta pertenecía a la corrien-

4 A. COUCHAUD, Choix d'Églises Bysantines en Grèce, París, 1842. Muchos de los planteamientos expuestos por André Couchaud al respecto de la caracterización del arte bizantino sirvieron como fuente de inspiración para otros trabajos de análisis y catalogación a lo largo de las décadas siguientes, Ch. TEXIER-R. POPPLEWEL PULLAN, Byzantine Architecture Illustrated by Examples of Edifices Erected in the East During the Earliest Ages of Christianity, with Historical and Archeological Descriptions, Londres, 1864.

5 M. DE VOGÜÉ, Syrie Centrale. Architecture civile et réligieuse du I er au VI siècle, París, 1865-1877.

6 Vid. al respecto J. DE LA RADA Y DELGADO, Viaje a Oriente de la Fragata “Arapiles” y de la comisión científica que llevó a su bordo, Barcelona, 1876; M. CHINCHILLA GÓMEZ, "El viaje a Oriente de la Fragata Arapiles", De Gabinete a Museo. Tres siglos de historia, cat. exp, Madrid, 1993, pp. 286-299; J. PASCUAL GONZÁLEZ, "Las jornadas en Siria y Palestina de Juan de Dios de la Rada y la expedición de la fragata de guerra 'Arapiles"”, J. M. CÓRDOBA ZOILO, R. JIMÉNEZ ZAMUDIO, C. SEVILLA CUEVA (eds.) El redescubrimiento de Oriente Próximo y Egipto. Viajes, hallazgos e investigaciones, Madrid 2001, pp. 31-50; Ibídem, "Don Juan de Dios de la Rada y Delgado y los expedicionarios de la fragata de guerra Arapiles en Tierra Santa", Arbor: Ciencia, Pensamiento y Cultura, 711-712 (2005), pp. 805-824; J. DE LA ASCENSIÓN SALAS ÁLVAREZ, "Las misiones científicas y el acrecentamiento de los fondos del Museo Arqueológico Nacional: la fragata Arapiles en Italia”, J. BELTRÁN FORTES, B. CACCIOTTI, B. PALMA (coords.), Arqueología, coleccionismo y antigüedad: España e Italia en el siglo XIX, Sevilla, 2007, pp. 603624; J. PASCUAL GONZÁLEZ, "Cinco días en Atenas: la estancia de los expedicionarios de la fragata blindada 'Arapiles' en Grecia en julio de 1871", Erytheia: Revista de Estudios Bizantinos y Neogriegos, 29 (2008), pp. 135-168.

7 R. MITJANA, "Estudios históricos sobre las Bellas Artes en la Edad Media. Arquitectura de los siglos XIII-XIV-XV”, El siglo pintoresco, 1 (1845). 
te bizantina ${ }^{8}$. Por aquel entonces, Alberto Lenoir proponía una serie de postulados mediante los cuales se podían destilar en una obra de arte los elementos bizantinos de los propiamente occidentales 9 . En esta circunstancia se produce el hallazgo del Tesoro de Guarrazar en $1858^{10}$, un descubrimiento que encajaba con jubilosa sencillez en los moldes historicistas propuestos por los ámbitos académicos de entonces. Pedro de Madrazo señalaba que la arquitectura tenida como visigoda se habría caracterizado por poseer un esqueleto romano cubierto por una epidermis bizantina. Quien canalizó con mayor solvencia estas pesquisas fue José Amador de los Ríos, que crea incluso el celebrado término "arte latino-bizantino" y lo aplica reiteradamente en sus estudios dedicados a los restos ornamentales de Guarrazar, Córdoba y Mérida entre 1861 y $1879^{11}$. Desde aquel momento se establece una metodología de análisis de las creaciones altomedievales hispánicas basada en la subordinación de las mismas a una variable de excelencia administrable según el grado de bizantinismo que se quería ver en ellas.

Coincidiendo con el cambio de siglo nos encontramos con la labor investigadora de Josef Strzygowski, quien en su afán por enaltecer el "genio germano" en las creaciones altomedievales encontró en el arte bizantino un cómplice de lujo para afirmar que el arte cristiano de Occidente había sido importado desde Oriente tras la época de las invasiones ${ }^{12}$. Esta valoración abrió de par en par las puertas a una impetuosa propensión hacia el rastreo de paralelismos tipológicos llevada a cabo por parte de los historiadores del arte europeos. "A" se parece a "B", ergo "A" está influido por "B", parecía ser la consigna. Esta corriente alcanzaba su auge en 1921 con la expedición arqueológica a Dura Europos. En palabras de Bianchi Bandinelli, "pareció que la explicación de las influencias orientales recibía una indiscutible confirmación" Así las cosas, en fechas inmediatamente anteriores a la Segunda Guerra Mundial, las corrientes germanistas y bizantinistas habían dejado completamente fuera del análisis de la creación artística occidental a cualquier competencia asociable a la autoctonía. Lo más paradójico de todo es que en aquellas fechas el arte bizantino del que tanto se hablaba no pasaba de ser un gran desconocido. Hubo que esperar a las intervenciones llevadas a cabo por Thomas Whittemore y su equipo en Estambul entre 1933 y 1952 para arrojar algo de luz sobre el modo en el cual el arte de Bizancio se hubo desarrollado en su órgano original ${ }^{14}$.

8 M. DE ASSAS, Álbum artístico de Toledo, Madrid, 1848.

9 A. LENOIR, "El Catolicón. Catedral de Atenas", M. J. GAILHABAUD (dir.) Monumentos Antiguos y Modernos, colección que constituye la Historia de la Arquitectura, Madrid, 1845.

10 P. A. ALONSO REVENGA, Historia del descubrimiento del Tesoro Visigodo de Guarrazar, Toledo, 1988; Ibídem, "El descubrimiento del Tesoro de Guarrazar", Toledo: Tierras y Pueblos, (3) 1997, pp. 17-22.

11 J. AMADOR DE LOS RÍOS Y SERRANO, El arte latino-bizantino y las coronas visigodas de Guarrazar. Ensayo histórico-crítico, Madrid, 1861; Ibídem, Monumentos latino-bizantinos de Mérida, Madrid, 1877; Ibidem y R. AMADOR DE LOS RÍOS Y VILLALTA, Monumentos latino-bizantinos de Córdoba, Madrid, 1879.

12 J. STRZYGOWSKI, Orient oder Rom? Beiträge zur geschichte Späantiken und frühchristlichen Kunst, Leipzig, 1900.

13 R. BIANCHI BANDINELLI, Del Helenismo a la Edad Media, Madrid, 1981, p. 145.

14 Th. WHITTEMORE, The Mosaics of Saint Sophia at Estambul, París, 4 vols., 1933-1952. 
Volviendo de nuevo a España cabe decir que en los años 40 del pasado siglo, Helmut Schlunk planteaba una serie de correlaciones entre el arte altomedieval hispánico y el bizantino desde un punto de vista primordialmente formal en el que el sostén ravenico jugaba un papel de gran importancia ${ }^{15}$. A él debemos la primera desestimación de la existencia de un foco de bizantinismo establecido en el Levante español durante la ocupación imperial entre 552 y 624 . El registro arqueológico le ha dado la razón, pues tal y como señala Cyril Mango, "no existe correspondencia directa entre reconquista bizantina y bizantinización" ${ }^{16}$. Sin embargo, Schlunk recurrió al estudio y a la datación de piezas por paralelismos hasta tal punto que podemos decir que desde entonces, el mito decimonónico del bizantinismo en España empezó a convertirse, mutatis mutandis, en un lugar común historiográfico llamado a generar un sinfín de contradicciones.

Durante los años 60 y 70 aparecieron una serie de propuestas en el panorama científico español que empezaban a llamar la atención sobre la existencia y la importancia de una dinámica creadora que, impulsada desde el vasto sustrato hispanorromano, habría de ser debidamente justipreciada a la hora de analizar la mayor parte del repertorio artístico tardoantiguo y altomedieval peninsular. Muchas de estas pesquisas, elaboradas entre otros por Palol o Fontaine, hubieron de ajustarse sin embargo a los patrones explicativos dominantes, en los cuales la recurrencia reiterada al referente artístico foráneo se encontraba ya profundamente enraizada. De esta forma, cualquier labor de detección destinada a individualizar posibles procedimientos artísticos de condición auto-derivativa quedó supeditada a la permanencia del modelo consensuado. Ello contribuyó a la aceptación de unos bloques crono-tipológicos cerrados, en los cuales innumerables obras quedaban atascadas en determinados cuellos de botella temporales, siendo quizás el del siglo VII el más representativo. ¿Qué sucedía con las realizaciones del siglo VIII? La respuesta venía formulada exactamente desde el mismo posicionamiento de subordinación: hay que esperar a una nueva influencia proporcionada por otro gran ente de oficialidad artística, esta vez el islámico.

En cuanto al conocimiento del arte bizantino y de las relaciones entre Hispania y el Imperio durante la Alta Edad Media hemos de decir que se ha producido un importante salto cualitativo y cuantitativo durante el último cuarto de siglo. A principios de los 70 García Moreno aludía a la ausencia de trabajos realizados en esta dirección ${ }^{17}$ e incluso a finales de los 80 , tal y como señalaba Pedro Bádenas, "hablar de bizantinismo en España resultaba aún pretencioso" ${ }^{18}$. A pesar de que en el dominio de la filología se habían venido realizando importantes avances en este sentido, es preciso señalar que en el ámbito puramente historiográfico se debió esperar hasta que en

15 H. SCHLUNK, "Relaciones entre la Península Ibérica y Bizancio durante la época visigoda", Archivo Español de Arqueología, 60 (1945), pp. 177-204; Ibídem, Byzantinische Bauplastik aus Spanien, Heildeberg, 1964.

16 C. MANGO, "La culture grecque et l'Occident au VIIIe siècle”, I problemi dell'Occidente nel secolo VIII, XX Settimane di studio del Centro italiano di studi sull'alto medioevo, (Spoleto, 1972), Spoleto, 1973, pp. 683-684.

17 L. GARCÍA MORENO, "Colonias de comerciantes orientales en la Península Ibérica, siglos V-VII", Habis, 3 (1972), pp. 127-154.

18 P. BÁDENAS DE LA PEÑA, "Los estudios bizantinos en España”, M. CORTÉS ARRESE (coord.), Toledo y Bizancio, Cuenca, 2002, p. 16. 
1993 Margarita Vallejo ofreciese un primer estudio en profundidad sobre las relaciones mantenidas entre Bizancio y la Península Ibérica durante la Tardoantigüedad ${ }^{19}$. Esa plataforma de análisis ha sido debidamente ampliada en los últimos años desde el terreno de la arqueología, en el cual hay que destacar las labores realizadas, entre otros, por Darío Bernal, Sebastián Ramallo o Jaime Vizcaíno. No debemos olvidar tampoco a otras figuras que, como Miguel Ángel Elvira o Miguel Cortés Arrese han potenciado considerablemente el conocimiento del arte de Bizancio en nuestro país.

Ahora bien, en cuanto al estudio de las manifestaciones artísticas realizadas en Hispania durante estos siglos cabe señalar que a día de hoy, con el "arte latino-bizantino" portando más de un siglo a sus espaldas, no nos equivocaríamos demasiado al decir que en los ámbitos académicos, científicos y divulgativos sigue confiriéndose un especial privilegio al Quellenforschung - estudio de fuentes- que nos proporcionan las influencias bizantinas siempre que un buen número de obras tardoantiguas y altomedievales sale a escena.

La invocación a las influencias orientales presenta, a nuestro juicio, múltiples puntos de fisura desde una perspectiva metodológica. Citaremos solamente algunos de ellos. Los grupos humanos establecidos en la cuenca del Mediterráneo, que en palabras de John Bury volvió a ser un lago romano tras las conquistas de Justiniano, no habían perdido en ningún momento los contactos existentes entre ellos desde la tardorromanidad, y ni mucho menos su condición y actividad creadora. Así, no fue necesario esperar a la apertura de un suministro artístico-referencial proporcionado por la oficialidad justinianea. Las conexiones interculturales producidas en la Cristiandad durante estos años fueron vehiculizadas por grupos humanos de índole tan diversa-sirios, egipcios, eslavos, norteafricanos, gálicos, judíos...- que parece mucho más coherente aceptar la existencia de una koiné compuesta por numerosas variantes artísticas de naturaleza dialectal que una noción tan amplia y nebulosa como la que se esconde tras la presumible tutela bizantina. A día de hoy existen aún varias lagunas en lo que respecta al arte bizantino de esta época. En el caso de la escultura decorativa podríamos incluso decir que poseemos un conocimiento mucho más profundo de las realizaciones occidentales que de las bizantinas, que es lo mismo que afirmar que conocemos mejor las supuestas consecuencias que las supuestas causas, lo cual no deja de resultar paradójico. Apelamos frecuentemente al anhelo de las élites occidentales por intentar copiar o imitar elementos propios del ceremonial bizantino cuando el conocimiento que estas poseían acerca de dichas escenificaciones se ha demostrado sumamente parcial ${ }^{20}$. Hablamos de orígenes orientales aludiendo al área constantinopolitana cuando esta misma fagocitó numerosas fórmulas artísticas procedentes de las provincias occidentales ${ }^{21}$. Recurrimos al nexo de la escultura de Rávena cuando esta presenta varios

19 M. VALLEJO GIRVÉS, Bizancio y la España tardoantigua (ss. V-VIII): Un capitulo de historia mediterránea, Alcalá de Henares, 1993.

20 J. ARCE MARTÍNEZ, "Ceremonial visigodo/ceremonial 'bizantino': un tópico historiográfico", I. PÉREZ MARTÍN-P. BÁDENAS DE LA PEÑA (eds.) Bizancio y la Península Ibérica. De la Antigüedad Tardía a la Edad Moderna, Madrid, 2004, p. 42.

21 A. PERTUSI, "Bisanzio e l'irradiazione della sua civiltà in Occidente nell'Alto Medioevo", Centri e vie di irradiazione della civiltà nell'Alto Medioevo. XI, Settimane di Studio del Centro Italiano di Studi sull'Alto Medioevo, Spoleto, 1964, p. 76. 
factores de conexión y datación con Oriente ciertamente cuestionables ${ }^{22}$. Pensamos en el tráfico de objetos como portadores de influencia y solemos omitir las vías de inspiración establecidas en base a algo tan importante en aquellos años como fue la oralidad y la descripción ${ }^{23}$. Damos por sentado que existió una estrecha conexión entre Oriente y Occidente cuando bizantinistas consagrados como Geanakoplos han demostrado que esta fase se caracteriza por contactos solamente esporádicos ${ }^{24}$. Alegamos la presencia de importaciones de obras de arte que en muchas ocasiones llegaron a Occidente en época pleno y bajomedieval. Por último, tomamos elementos como las plantas cruciformes como un síntoma de bizantinización, cuando según las investigaciones más recientes, todo parece indicar que en el caso hispano este enunciado no es sino un fabuloso espejismo. Con respecto de este tipo de edificaciones, María de los Ángeles Utrero ha señalado con agudeza que la escasez numérica de manifestaciones arquitectónicas de esta época con respecto del amplio volumen conservado de escultura decorativa, ha llevado a utilizar esta última como una matriz al servicio del estudio de la primera, lo cual ha generado un elevado número de obstáculos que dificultan el estudio de ambas ${ }^{25}$.

La detección de influencias en este período, orientales o no, presenta un nivel de contingencia desplegable en varios grados. Así, si admitiésemos una secuencia lineal de ascendentes de inspiración, por ejemplo Constantinopla-Rávena, Rávena-Mérida, Mérida-Toledo, etc., tendríamos que haber acertado en cada correspondencia de la concatenación propuesta sin margen de error. En caso contrario habríamos enunciado un bloque de transmisiones engañoso al omitir en él la eventual adhesión a la secuencia de otras líneas de ascendencia. Por esta razón, consideramos que a la hora de evaluar una potencial influencia de las realizaciones orientales en aquellas hispanas hemos de considerar tres elementos fundamentales: 1. Variabilidad lineal (si erramos en la detección de una influencia, el error se traslada al análisis de otras piezas, creando un sistema contradictorio); 2. Extemporaneidad (el ascendente de una obra no viene necesariamente determinado por una creación o tendencia cronológicamente aledaña); 3. Probabilidad de endogénesis sincrónica (un mismo fenómeno puede producirse simultáneamente en diferentes espacios sin que exista un contacto entre ellos). Al mismo tiempo, hemos de considerar las diferencias inherentes a la naturaleza de las conexiones, las cuales pueden dividirse en deliberadas-conscientes (imitación) e indeliberadas-maquinales (derivación).

Negar la existencia de una circulación de ideas, conceptos jurídicos, mercancías y personas físicas en el mundo mediterráneo durante esta época sería una irresponsabilidad por nuestra parte. No exigir prudencia y espíritu crítico a la hora de analizar el impacto que estos elementos tuvieron en las realizaciones artísticas también lo sería. Por último, es preciso señalar que el tráfico de objetos de lujo al que tanto se ha

22 G. VALENTI ZUCCHINI-M. BUCCI, "I sarcofagi a figure e a carattere simbolico", G. BOVINI (dir.), "Corpus" della scultura paleocristiana bizantina ed altomedievale di Ravenna, Roma, 1968, p. 8.

23 A. BRAVO GARCÍA, Bizancio. Perfiles de un Imperio, Madrid, 1997, pp. 55 y ss.

24 D. J. GEANAKOPLOS, Interaction of the "Sibling" Byzantine and Western Cultures in Middle Ages and Italian Renaissance (330-1600), New Haven- Londres, 1976, pp. 3 y ss.

25 M. A. UTRERO AGUDO, "Late Antique Churches in the South-Eastern Iberian Peninsula: The Problem of Byzantine Influence”. Millenium, 5 (2008), pp. 191-212. 
apelado como fuente de inspiración, debió ser insuficiente como para, según opinión de Jean Marie Hoppe, crear un efecto de moda de recurrencia sistemática o regular ${ }^{26}$. Consideramos que si se otorga al discurso de las influencias orientales en el arte altomedieval hispánico la mesura justa, tal vez accedamos a un conocimiento más profundo de los dos miembros integrantes del teórico diálogo. Podremos conferir al arte bizantino una dimensión más real si le liberamos del fatigoso rol de acreedor y consignatario de formulaciones estéticas que se le ha otorgado durante décadas. En el caso del arte hispánico, una moderación en la búsqueda de semejanzas y aires de familia existentes en obras lejanas nos permitiría prestar una mayor y muy valiosa atención a los procesos internos de transformación y permuta.

Percy Shelley dijo una vez que éramos todos griegos. Mucho tiempo después Borges matizó “...pero en el exilio”. Desde una óptica cultural macroscópica creemos que a ninguno de ellos le faltó razón. Ahora bien, aplicar estos preceptos a un hecho tan insondable como lo es la necesidad de producir arte es una historia bien distinta. En él, una imagen es un mundo. Dos, un arma de doble filo.

26 J. M. HOPPE, "Le corpus de la sculpture visigothique: libre parcours et essai d'interprétation", L. CABALLERO y P. MATEOS (eds.), Visigodos y Omeyas: Un debate entre la Antigüedad Tardía y la Alta Edad Media , Madrid, 2001, p. 324. 